\title{
The Lack of Emx2 Causes Impairment of Reelin Signaling and Defects of Neuronal Migration in the Developing Cerebral Cortex
}

\author{
Antonello Mallamaci, ${ }^{1}$ Sara Mercurio, ${ }^{1}$ Luca Muzio, ${ }^{1}$ Chiara Cecchi, ${ }^{1}$ Celia Leonor Pardini, ${ }^{1}$ Peter Gruss, ${ }^{2}$ and \\ Edoardo Boncinelli 1,3 \\ ${ }^{1}$ Department of Biological and Technological Research (DIBIT), Istituto Scientifico H. San Raffaele, 20132 Milano, Italy, \\ 2Max-Planck Institute of Biophysical Chemistry, 37018 Goettingen, Germany, and 3Molecular and Cellular Pharmacology, \\ Consiglio Nazionale delle Ricerche, 20129 Milano, Italy
}

\begin{abstract}
Neocorticogenesis in mice homozygous for an Emx2 null allele is the topic of this article. The development of both main components of neocortex, primordial plexiform layer derivatives and cortical plate, was analyzed, paying special attention to radial migration of neurons forming the cortical plate. The products of the Reelin gene, normally playing a key role in orchestrating radial migration of these neurons, display normal distribution at the beginning of the cortical neuronogenesis but are absent in the neocortical marginal zone of the mutant mice
\end{abstract}

Emx2 is a vertebrate homeobox gene related to the Drosophila gap gene ems (Dalton et al., 1989). It was originally found in mouse and in man (Simeone et al., 1992a,b) and subsequently isolated in chicken (A. Mallamaci, unpublished results), frog (Pannese et al., 1998), and fish (Morita et al., 1995; Patarnello et al., 1997). Its expression in the anterior CNS of the developing mouse embryo has been extensively described (Simeone et al., 1992a,b; Gulisano et al., 1996; Mallamaci et al., 1998). Emx2 has been knocked-out in mice by homologous recombination in embryonic stem (ES) cells. Homozygous mutant mice die perinatally, probably because of the absence of kidneys. The archicortex of these animals is heavily affected; the dentate gyrus is missing, and the hippocampus and the medial limbic cortex are greatly reduced in size. The olfactory bulb is also disorganized, and the olfactory nerve fails to project to it. Lamination defects have been reported to occur in the neocortex (Pellegrini et al., 1996; Yoshida et al., 1997).

It has been suggested that Emx 2 plays an important role in the formation of the abstract areal code specifying the dorsal telencephalon regional identity (Simeone et al., 1992b; Shimamura et al., 1995; Yoshida et al., 1997). Ablation of this early basic

\footnotetext{
Received Feb. 9, 1999; revised Nov. 11, 1999; accepted Nov. 15, 1999.

This work was supported by grants from the European Community BIOTECH and BIOMED Programmes, the Telethon-Italia Programme, the Italian Association for Cancer Research (the AIRC), and the Armenise-Harvard Foundation. We thank Pierre Gressens for the RC2 antibody, Giacomo Consalez for reeler founder mice, Vania Broccoli and Larry Wrabetz for comments and suggestions, Mario Azzini for photographic assistance, and Giorgio Corte, who collaborated previously with us in generating the anti-EMX1 antibody. A special thanks to Alessandro Bulfone for his helpful criticism and encouragement. Animals were handled as recommended by the Institutional Animal Care and Use Committee of H. San Raffaele.

Drs. Mercurio and Muzio contributed equally to this work.

Correspondence should be addressed to Antonello Mallamaci, Staff Scientist, Unit of Molecular Biology of Development, DIBIT, H. San Raffaele, via Olgettina 60, 20132 Milano, Italy. E-mail: mallamaci.antonio@hsr.it.

Dr. Mercurio's present address: National Institute of Medical Research, Medical Research Council, Mill Hill, The Ridgeway, NW7 1AA London, U.K.

Copyright (C) 2000 Society for Neuroscience $0270-6474 / 00 / 201109-10 \$ 15.00 / 0$
}

at the time when the cortical plate is laid down. As a consequence, the development of radial glia is impaired, and neurons making up the cortical plate display abnormal migration patterns. In addition, restricted defects along the rostrocaudal and the mediolateral axes are present in the subplate, suggesting an Emx2-specific role in priming the proper development of this layer.

Key words: neocortex; Emx2; Cajal-Retzius cells; reeler; radial glia; subplate function could account for some of the most relevant features of the mutant mice, such as defects in the limbic area (Yoshida et al., 1997). Additionally, more specific functions have been proposed to be acted by Emx2 later in development. Their impairment might result in more subtle traits of the mutant phenotype, e.g., poorly characterized neocortical lamination defects (Yoshida et al., 1997). This late contribution of Emx2 to neocortical development was the main object of our study.

The formation of the cerebral cortex is a biphasic process. Early postmitotic neurons accumulate at the marginal edge of the cortical wall, forming the primordial plexiform layer (PPL). Then, later born neurons climb along fascicles of radial glia and infiltrate the PPL. They split it into the more superficial marginal zone (MZ) and the deeper subplate (SP) and accumulate between them, making up the cortical plate (CP) (Marin-Padilla, 1978). Careful analysis of the development of both PPL derivatives and $\mathrm{CP}$ in mutant embryos allowed us to clarify the key role played by Emx2 in orchestrating the process of radial migration, as well as in priming the development of the SP.

Hints about a possible association between Emx2 and neuronal migration recently came from the finding of large amounts of EMX2 protein in Cajal-Retzius (CR) cells in the MZ of late gestation mouse embryos (Mallamaci et al., 1998). CR cells are among the most relevant players in orchestrating the radial migration of CP neurons (Marin-Padilla, 1988, 1998; Del Rio et al., 1995), partly through the protein product of the Reelin gene (Reln) (D'Arcangelo et al., 1995, 1997; D'Arcangelo and Curran, 1998; Ogawa et al., 1995), and it is conceivable that EMX2 protein is necessary to allow CR cells to perform this function. As expected, we found that late gestation $E m \times 2^{-1-}$ embryos lacked Reelin mRNA in their MZ and consequently displayed severe impairment of neuronal radial migration.

The SP is a heterogeneous cortical layer (Antonini and Shatz, 1990), critical for the proper development of the cerebral wiring. It is involved in establishing transient, both corticopetal and 
cortif ugal initial connections, which forerun and allow the proper development of the permanent ones (Ghosh, 1995 and references therein). Very little is known about the genetic control of the SP development at the moment. Interestingly, we found that specific neuronal subpopulations of the SP, which normally does not express Emx2, are selectively affected in Emx $2^{-1-}$ embryos at axial locations just corresponding to areas of the ventricular zone (VZ) that normally express Emx2 at the highest levels. This suggested that Emx2 could play an essential, specific role in priming the proper development of these neurons.

\section{MATERIALS AND METHODS}

Animal husbandry, bromodeoxyuridine labeling, and embryo harvesting. Emx $2^{-/+}$female mice of mixed C129Sv/J-C57Bl6 genetic background (Pellegrini et al., 1996) were mated overnight with $E m \times 2^{-/+}$males of similar genetic background and inspected at 9.00 A.M. on the following day for the presence of vaginal plug; noon of this day was assumed to correspond to embryonic day 0.5 (E0.5). In a similar way, C57B16 mice heterozygous for the Reeler Edimburgh null allele were intercrossed. When appropriate, at selected times, pregnant dams were injected intraperitoneally with $100 \mu \mathrm{g}$ of bromodeoxyuridine (BrdU) per gram of body weight. At scheduled times, pregnant females were anesthetized by $\mathrm{CO}_{2}$ and killed by cervical dislocation. Embryos were harvested, genotyped according to Pellegrini et al. (1996) and D'Arcangelo et al. (1995), and further processed.

Immunohistochemistry. Embryos were treated in two different ways depending on the kind of analysis to be performed. In the case of immunohistochemistry with the monoclonal antibody against the glial $\mathrm{RC} 2$ epitope, they were embedded fresh in OCT, frozen on dry ice, and cut by cryostat at $50 \mu \mathrm{m}$. Sections were mounted on Fischer SuperFrost Plus slides, air dried for $30 \mathrm{~min}$ at room temperature (RT), and stored at $-80^{\circ} \mathrm{C}$. Subsequently, they were washed in PBS and post-fixed in absolute $\mathrm{MeOH}$ at $-20^{\circ} \mathrm{C}$ for $8 \mathrm{~min}$. Slides were rehydrated at RT by descending methanolic series and finally processed for immunohistochemistry. In the case of other immunohistochemistries, embryos were fixed upon harvesting in paraformaldehyde $4 \%$ PBS overnight at $+4^{\circ} \mathrm{C}$ and then washed, dehydrated, and embedded in wax according to standard protocols. In these cases, embryos were subsequently cut at $10 \mu \mathrm{m}$ by a microtome, and sections were mounted on Fischer SuperFrost Plus slides. Subsequently, samples were dewaxed by xylene, rehydrated in descending ethanolic series, and further processed. Specific treatments preceded the detection of some antigens. Before $\alpha$-EMX1 immunohistochemistry, the antigen was unmasked by boiling samples in $10 \mathrm{~mm}$ sodium citrate, $\mathrm{pH}$ 6.0, for 5 min and allowing them to cool down slowly. In the case of BrdU detection to depurinate genomic DNA and make the epitopes accessible, slides were kept in $2 \mathrm{M} \mathrm{HCl}$ for $30 \mathrm{~min}$ at $60^{\circ} \mathrm{C}$ and then neutralized in $0.1 \mathrm{~m}$ borate buffer, $\mathrm{pH} 8.5$, for $15 \mathrm{~min}$ at $\mathrm{RT}$. In general, subsequent steps of immunohistochemistry were performed according to Mallamaci et al. (1998). The following primary antibodies were used: $\alpha$-BrdU, mouse monoclonal (Becton Dickinson, Mountain View, CA), 1:100; $\alpha$-calretinin, rabbit polyclonal (Swant), 1:100; $\alpha$-EMX1, rabbit polyclonal (Briata et al., 1996), 1:400; $\alpha$-neuron-specific class III $\beta$-tubulin, mouse monoclonal (clone TuJ1; BabCo, Richmond, CA), 1:100; $\alpha$-microtubuleassociated protein 2 (MAP2), mouse monoclonal (clone AP20; Boehringer Mannheim, Indianapolis, IN) 1:100; and $\alpha$-RC2, monoclonal, 1:1 (Misson et al., 1988).

In situ hybridization. Radioactive and nonradioactive in situ hybridizations were performed according to Gulisano et al. (1996) and Bovolenta et al. (1997), respectively. For the detection of Oct6, an Oct6 radiolabeled probe corresponding to the entire coding region (Meiyer et al., 1990) was used. For Reln, a Reln antisense digoxygenated probe corresponding to nucleotides 5818-5973 (D’Arcangelo et al., 1995) was used.

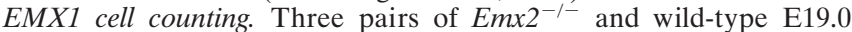
embryos were frontally sectioned at $10 \mu \mathrm{m}$, and for each embryo, every 13th section was kept. For each section, the cortical sector was partitioned in 16 equally spaced bins, which were numbered from ventricular to marginal; each bin was further divided in two hemibins, one medial (M) and one lateral (L), by the radial line intersecting the corticostriatal notch. Heavily $\alpha$-EMX1-reactive cells located in hemibins 5, 6, and $7 \mathrm{M}$ and 5, 6, and $7 \mathrm{~L}$ were counted by two different operators. Data were averaged, and the total numbers of cells located in all 5, 6, and $7 \mathrm{M}$ and all 5, 6, and $7 \mathrm{~L}$ hemibins of $E m \times 2^{-1-}$ and wild-type embryos were calculated and compared.
Graphics. BrdU-labeled cells were counted as explained in the legend of Figure 4. Graphics were generated on a MacIntosh G3 computer (Apple Computers, Cupertino, CA) by Microsoft (Seattle, WA) Excel software and processed by Adobe Photoshop 5.0 software (Adobe Systems, San Jose, CA).

Photography. Photos were taken by a Nikon (Tokyo, Japan) Eclipse 600 microscope and an SV MICRO CV3000 digital microscope camera. Electronic files were processed on a MacIntosh G3 computer by Adobe Photoshop 5.0 software.

\section{RESULTS \\ Development of marginal zone and subplate}

The development of the PPL derivatives, MZ and SP, was analyzed by scoring the expression of several specific markers: among them, CaR, EMX1, and Reln mRNA.

At E15.5, the Ca-binding protein calretinin ( $\mathrm{CaR})$ is normally restricted to CR cells of layer I and to a cellular subpopulation of the SP (Fig. $1 a-c$ ). No $\alpha$-CaR immunoreactivity was detected in the $\mathrm{MZ}$ of mutant embryos, except for a very few labeled cells located in the medialmost part of the mantle, in the presumptive cingulate cortex and hippocampal anlage (Fig. 1d-f). The intermediate, $\mathrm{SP}$-associated $\mathrm{CaR}$ stripe, normally detectable along the entire rostrocaudal length of the developing cortex (Fig. 1a-c), was restricted in the mutant animals to the rostralmost pallium, being absent at the level of the foramen of Monro and more posteriorly (Fig. 1d-f). Similar differences were found between wild-type and mutant animals at approximately the end of the gestational life (data not shown).

In E19.0 wild-type embryos, $\alpha$-EMX1 stains three main cortical domains. Plenty of lightly labeled cells are in the CP in which they form two broad and quite distinct bands. Numerous immunoreactive cells lie in the transitional field (TF), displaying a graded signal, higher medially than laterally. And finally, a very thin band, formed by heavily stained cells, can be easily distinguished in the SP (Fig. 1g, arrowheads). Few EMX1-positive cells were

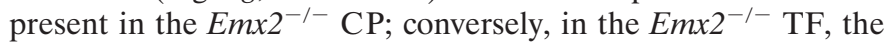
graded expression of the protein was retained (Fig. 1h). Remarkably, less heavily $\alpha$-EMX1-immunoreactive cells were detectable in the Emx $2^{-1-}$ SP and were mainly restricted to the lateralmost part of the telencephalic wall (Fig. $1 h$, arrowheads). In knock-out embryos, the total number of these cells was reduced to $40 \%$ compared with wild-type animals. This reduction was not uniform. Cells located laterally to the corticostriatal notch were reduced to $65 \%$, and those located medially to this notch were reduced to $\sim 25 \%$ (data not shown).

In the cerebral cortex of wild-type embryos, since E11.5 and up to birth, Reln mRNA is specifically detectable in CR cells, located in the MZ just underneath the pia and spread along the entire cortex (Fig. $2 a, c, e-g, k$ ); starting from E19, additional small Relnexpressing cells can be found in the deep CP (Fig. 2k). The distribution of Reln-expressing cells in E11.5 Emx2 $2^{-1-}$ embryos basically paralleled that of wild-type ones (Fig. $2 b$ ). Differences between knock-out and wild-type animals were detectable starting from E13.5. At this stage, in mutant animals, both lateral neocortex and presumptive paleocortex overlying the ganglionic eminence were almost completely free of any Reln RNA, whereas plenty of tightly clustered Reln-expressing cells could be detected in the MZ of the medial cortical primordium (Fig. 2d). At E15.5, differences were even more pronounced. At this stage, only a few Reln-expressing cells were present in the cortical MZ of Emx $2^{-/-}$ embryos, reproducing the distribution of $\alpha$-CaR-immunoreactive cells in the same animals (Fig. $2 h-j$ ). Reln-expressing cells were restricted to septum, cingulate cortex, and hippocampal anlage, 


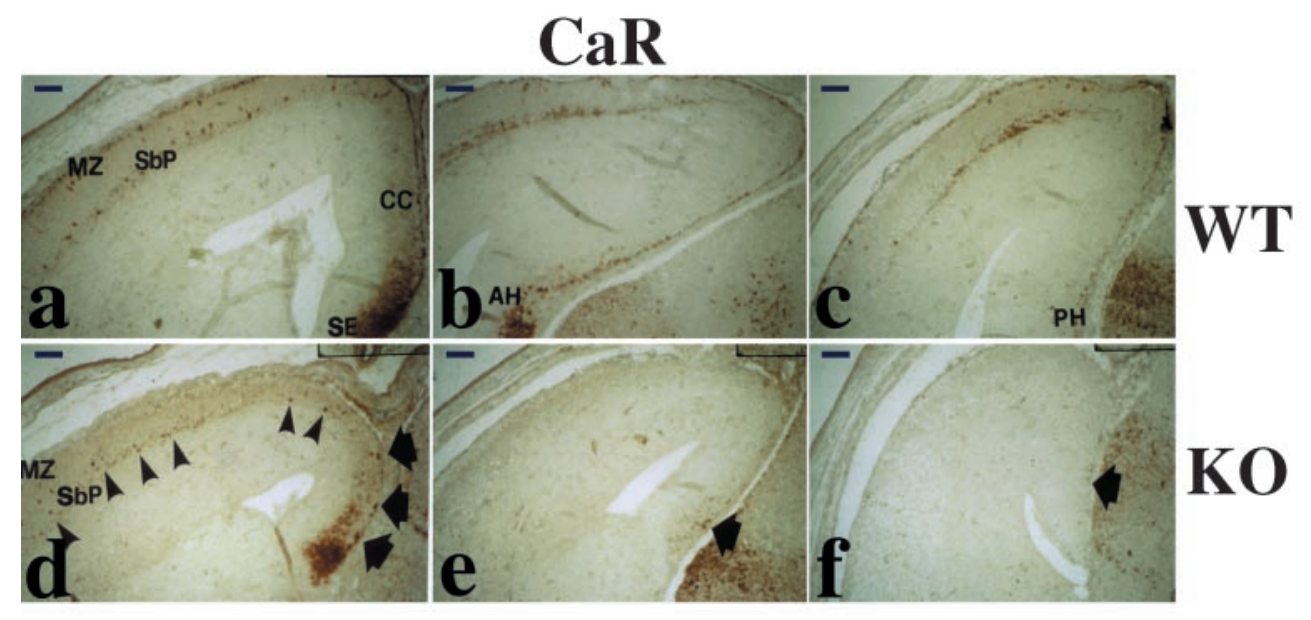

EMX1

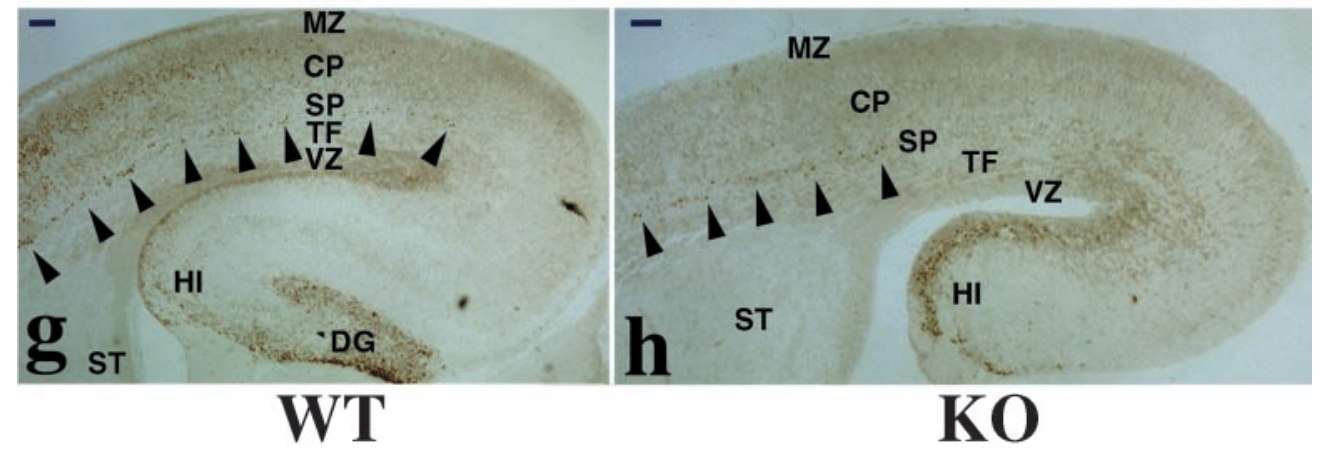

Figure 1. $\mathrm{CaR}$ and EMX1 in the telencephalon of wild-type and $E m x 2^{-/-}$late gestation embryos. $a-f$, Here is reported the distribution of CaR protein on frontal rostral $(a, d)$, intermediate $(b, e)$, and caudal $(c, f)$ sections of E15.5 wild-type $(a-c)$ and Emx $2^{-/-}(d-f)$ telencephalons. Medial is to the right. In wild-type embryos, $\mathrm{CaR}$ is detectable in septum $(a)$, cingulate cortex $(a)$, and presumptive hippocampus $(b, c)$. CaR is also present in the neocortex throughout its entire anteroposterior length. Here, it is distributed in two bands, corresponding to subplate and marginal zone $(a-c)$. Emx $2^{-I-}$ embryos express $\mathrm{CaR}$ in septum, cingulate cortex ( $d$, arrows), and, to lesser extent, in the hippocampal anlage (e, $f$, arrows). In their neocortex, CaR expression is confined to the rostralmost subplate ( $d$, arrowheads); no signal can be detected in the midcaudal subplate $(e, f)$ or in the entire marginal zone $(d-f)$. $g, h$, Distribution of EMX1 on midfrontal sections of E19 wild-type $(g)$ and Emx2 $2^{-/}(h)$ cerebral cortexes. Medial is to the right. In both cases, the protein is scarce in the ventricular zone and abundant in the deep part of the transitional field $(g, h)$. In the wild-type cortex, a row of heavily labeled cells is detectable in the subplate, extending from the lateral cortex, which overlies the striatum up to the medial wall of the telencephalon ( $g$, arrowheads). In the mutant animals, similarly labeled cells can be found at the same depth; however, they are much less numerous and are prevalently restricted to the lateralmost part of the wall ( $h$, arrowheads). Plenty of weakly labeled cells, approximately arranged in two broad stripes, can be found in the cortical plate of wild-type embryos $(g)$; only a few lightly stained cells can be detected at corresponding locations in mutant brains $(h)$. $A H$, Anterior hippocampus; $C C$, cingulate cortex; $C P$, cortical plate; $D G$, dentate gyrus; $H I$, hippocampus; MZ, marginal zone; $P H$, posterior hippocampus; $S E$, septum; $S P$ (or $S b P$ ), subplate; $S T$, striatum; $T F$, transitional field; $V Z$, ventricular zone. Scale bar, $100 \mu \mathrm{m}$.

whereas in neocortex they were absent. Ectopic, scattered Reln mRNA-positive cells were found in the TF of mutant embryos, being more numerous caudally than rostrally (Fig. $2 h-j$ ). Similar distribution of Reln-expressing cells was also found in the MZ of

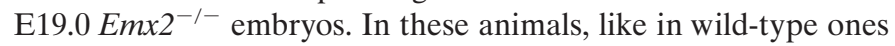
at the same stage, it was possible to detect plenty of cortical nonmarginal small Reln-expressing cells; however, differently from wild-type ones, these cells were not clustered in a narrow radial band but were dispersed throughout the entire width of the cerebral wall (Fig. $2 l$ ).

In summary, in late $E m x 2^{-1-}$ embryos, $\mathrm{CaR}$ and Reln mRNA were absent in the entire neocortical MZ, CaR was undetectable in the caudal SP, and EMX1 was prevalently reduced in the medial SP. Downregulation or disappearance of these markers could be consequence of the absence of cells normally expressing them; alternatively, it could arise from abnormal behavior of these cells. This argument will be analyzed further in Discussion.

\section{Radial migration of neurons belonging to the cortical plate}

The finding that late Reln expression in the neocortical MZ of $E m \times 2^{-1-}$ mice was absent strengthened our expectation that radial migration of late born neurons toward the CP could be deeply perturbed in these mice, possibly in a reeler-like way. It was for this reason that we decided to study neuronal radial migration in the neocortex of Emx2 mutant mice.

This problem was first approached by monitoring the distribution of two molecules: the neuron-specific class III $\beta$-tubulin and Oct-6 mRNA.

The monoclonal antibody TuJ1 selectively recognizes the neuron-specific class III $\beta$-tubulin, one the early markers expressed by postmitotic neuronal cells (Lee et al., 1990; Easter et al., 1993). In E15.5 wild-type animals, it stains the layers of the cerebral cortex from the subventricular zone (SVZ) to the MZ, with different intensities; almost no reactivity can be found in the 
Figure 2. Reln mRNA in the telencephalon of wild-type and $E m \times 2^{-1-}$ embryos. a-d, Reln mRNA on midfrontal sections of E11.5 $(a, b)$ and E13.5 $(c, d)$ wild-type $(a, c)$ and $E m x 2^{-1}$ $(b, d)$ embryos. In wild-type embryos of both stages, Reln is expressed in a ring of cells located in the marginalmost part of the telencephalic wall, including the ganglionic eminence. In Emx 2 knock-out mice, the distribution of Reln-positive cells, basically normal at E11.5 (b, arrowheads), looks substantially altered at E13.5 $(d)$; at this stage, almost no Reln-positive cell is detectable in the lateral presumptive cortex, except a few of them located above the ganglionic eminence ( $d$, arrowheads), whereas plenty of them are tightly clustered in the marginal medial cortical wall ( $d$, arrows). $e-j$, Here is reported the distribution of Reln mRNA on frontal rostral $(e, h)$, intermediate $(f, i)$, and caudal $(g, j)$ sections of E15.5 wild-type $(e-g)$ and $E m \times 2^{--}(h-j)$ telencephalons. Medial is to the right. In wild-type embryos, marginal rings of Reln-expressing cells can be detected at all rostrocaudal levels $(e-g)$; specific clustering of these cells takes place in the hippocampus $(g)$. The telencephalon of $E m x 2^{-/-}$embryos is severely deprived of Reln mRNA. In these animals, Reln-positive neurons are still detectable in the marginal zone of septum $(h$, small black arrow), cingulate cortex $(h, i$,open arrow), and hippocampus ( $j$, large black arrow), but almost completely not in the neocortical marginal zone $(h-j)$. Ectopic, scattered positive cells can be found in the developing neocortex, more numerous at the caudalmost levels $(h-j$, arrowheads). $k, l$, Reln mRNA on midfrontal sections of neocortices of E19.0 wild-type $(k)$ and Emx2 $2^{-1-}(l)$ embryos. Large Reln-positive Cajal-Retzius neurons can be found in the marginal zone of the wild-type cortex $(k$, white arrows) but not in the corresponding layer of the mutant one $(l)$. Small labeled cells are in the outer half of the wild-type cortical plate $(k$, white arrowheads); small Reln-positive cells are irregularly spread throughout the entire width of the mutant cortex ( $l$, white arrowheads). $C C$, Cingulate cortex; $C P$, cortical plate; $C X$, cortex; $G E$, ganglionic eminence; $H I$, hippocampus; $M Z$, marginal zone; $N C$, neocortex; $S E$, septum; $S P$, subplate; $T F$, transitional field; $V Z$, ventricular zone. Scale bar, $100 \mu \mathrm{m}$.

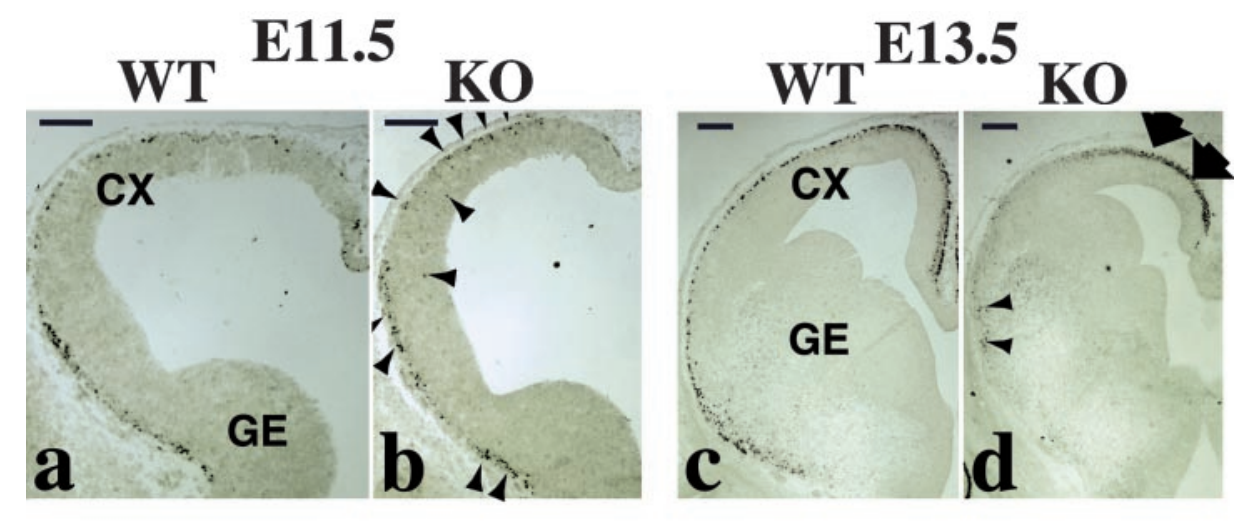

E15.5
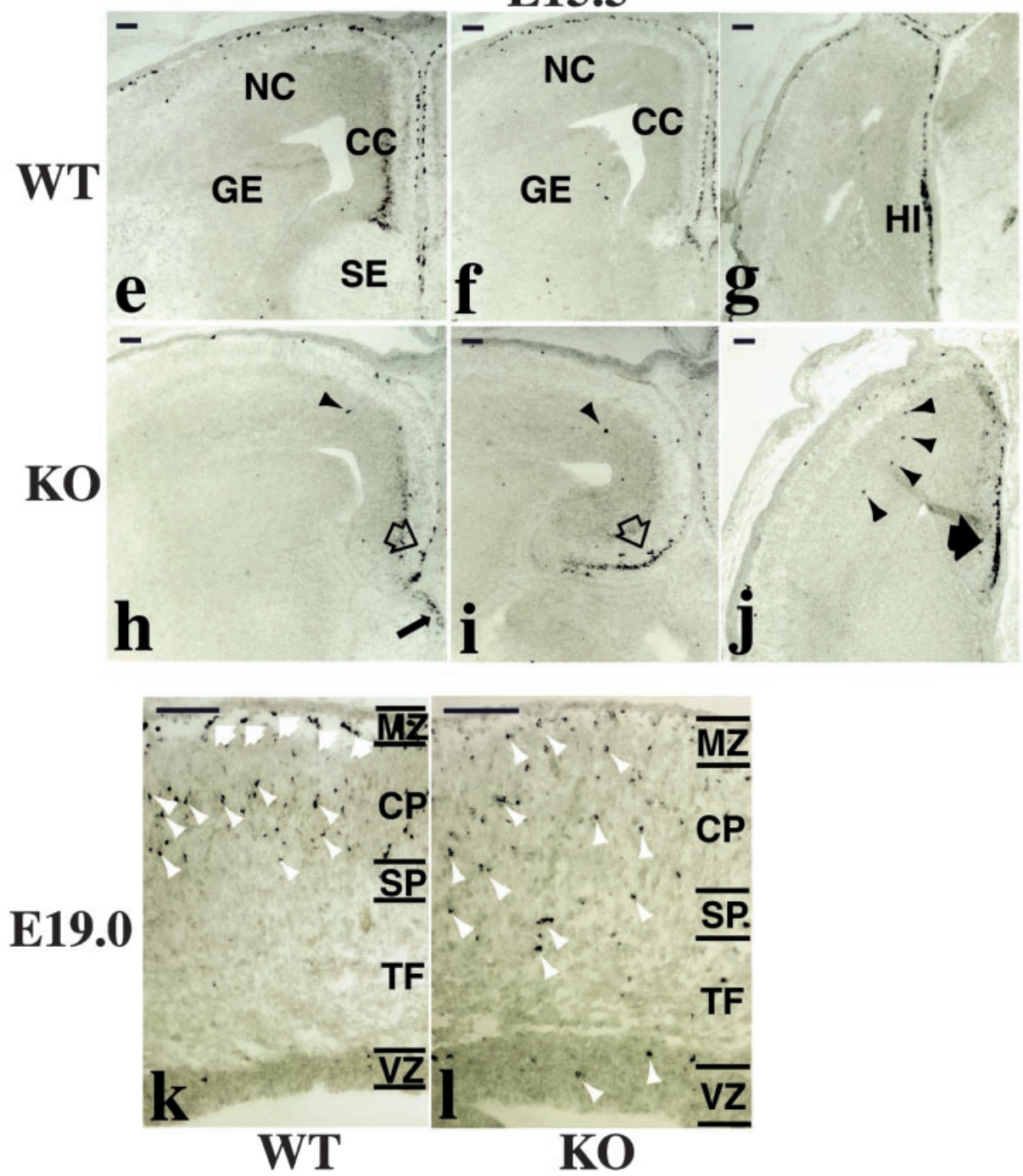

VZ (Fig. 3c,e). In the case of $E m \times 2^{-1-}$ embryos, numerous TuJ1-positive cells were present in the cortical VZ; the TF displayed a conspicuous accumulation of intensely immunoreactive cells (Fig. $3 d, f$ ) that was absent in wild-type embryos. Even if we cannot rule out alternative explanations (for example, accumulations of $\mathrm{TuJ} 1$ in the SVZ could correspond to neurons tangentially migrating from the ganglionic eminence to the cortex; see Anderson et al., 1997 and references therein), it is conceivable that at least ectopic TuJ1-positive cells found in the
VZ could include neuronal cells that locally came out of the mitotic cycle and were migrating, slower than normal, from the $\mathrm{VZ}$ toward their final radial location.

Oct- 6 has been described to be specifically expressed in the rat by neurons of layer $\mathrm{V}$, from the middle of their migration up to the adult stage (Frantz et al., 1994). At E15.5, in both Emx2 $2^{-1-}$ and wild-type mouse embryos, Oct-6 RNA was detectable throughout the TF, especially in the outer part of this layer (Fig. $3 a, b)$. The wild-type cortex displayed an additional Oct6 signal in 

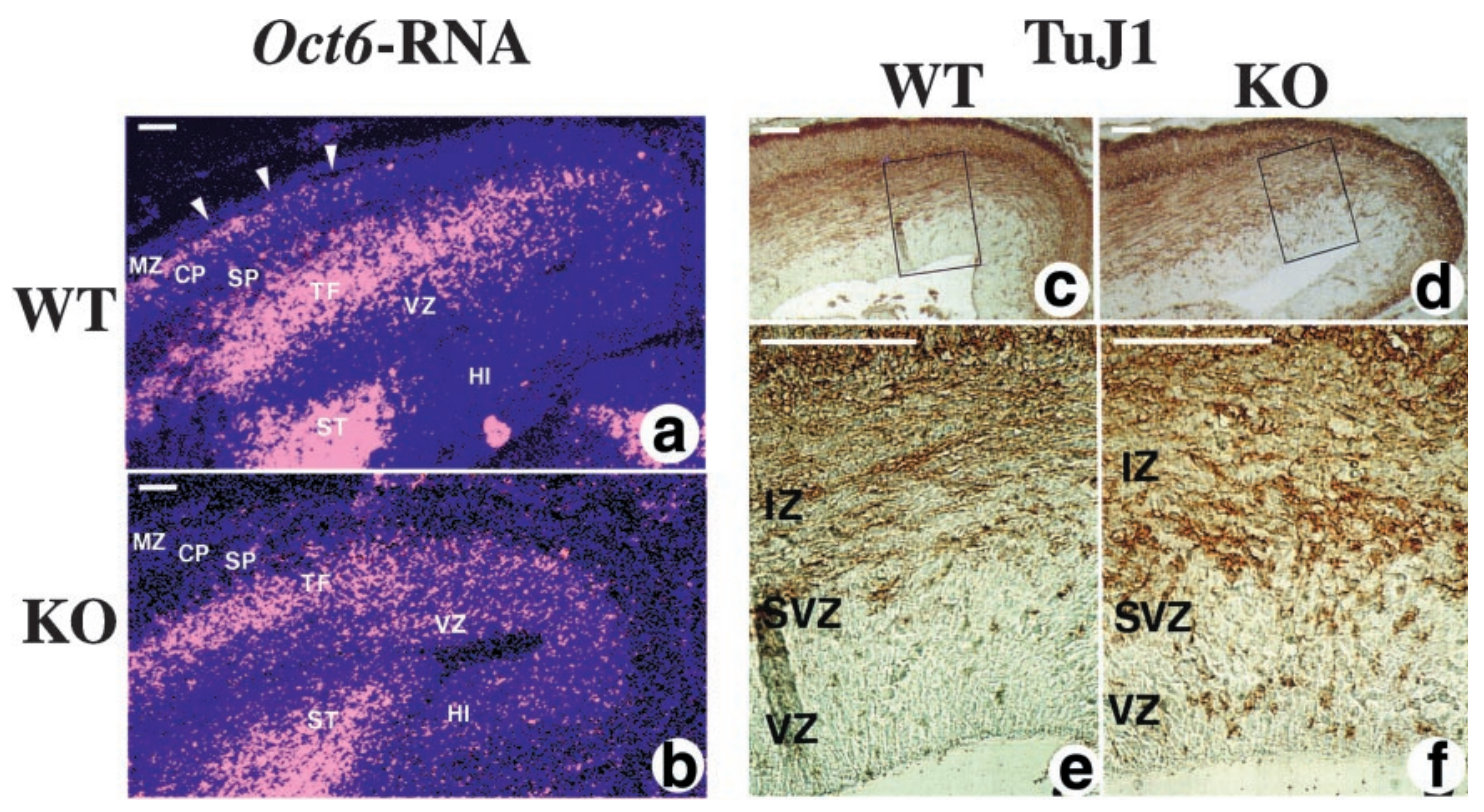

Figure 3. Neuron-specific class III $\beta$-tubulin and Oct6 mRNA in the telencephalon of wild-type and Emx $2^{-/-}$late gestation embryos. $a, b$, Distribution of Oct6 mRNA in the telencephalon of E16.0 wild-type $(a)$ and $E m x 2^{-/-}(b)$ embryos; frontal sections, slightly caudal to the level of the foramen of Monro. Medial is to the right. In both cases, the RNA is in the developing striatum, as well as in the pallium. In the cerebral cortex, the signal is detectable throughout the transitional field. It gives rise to an very intense band in the outer part of this layer, just underneath the subplate $(a, b)$. In the outer lateral cortical plate of the wild-type cortex, an additional thin Oct6 band can be found, possibly corresponding to the first neurons belonging to the prospective layer $\mathrm{V}$, which overcame the subplate and settled at their final radial level ( $a$, white arrowheads). No trace of this additional signal can be detected at corresponding locations in the Emx $2^{-1-}$ brain $(b) . c-f$, Distribution of the neuron-specific class III $\beta$-tubulin on middle frontal sections of dorsal telencephalon in wild-type $(c)$ and $E m x 2^{-1-}(d)$ embryos, revealed by the monoclonal antibody TuJ1. In $e$ and $f$, magnifications of boxed areas of $c$ and $d$ are represented, respectively. In normal embryos, immunoreactivity is detectable throughout the entire width of the cortical wall, except the ventricular and the inner subventricular zones $(c, e)$. In $E m x 2^{-/-}$animals, several scattered TuJ1-positive cells can be found in the ventricular zone, and numerous clustered immunoreactive cells lie around the border between subventicular and intermediate zones $(d, f)$. $C P$, Cortical plate; $H I$, hippocampus; $I Z$, intermediate zone; $M Z$, marginal zone; $S P$, subplate; $S T$, striatum; $S V Z$, subventricular zone; $T F$, transitional field; $V Z$, ventricular zone. Scale bar, $100 \mu \mathrm{m}$.

the outer lateral $\mathrm{CP}$, possibly corresponding to the first neurons belonging to the perspective layer $\mathrm{V}$, which overcame the SP and settled at their final position (Fig. $3 a$ ). No trace of these positive cells could be found in Emx $2^{-/-}$brains (Fig. $3 b$ ), in agreement with the hypothesis of a possible impairment of neocortical radial migration.

To systematically compare the migratory behavior of cells fated to form the neocortex in Emx2 null versus Emx2 wild-type embryos, we pulse-labeled neurons born at E12.0, E13.5, and E15.0 by BrdU and scored their radial distributions through the neocortical wall of E19 Emx2 $2^{-/-}$and wild-type embryos (Fig. $4 a-h$ ). Data were collected, processed, and graphically synthesized as explained in the legend of Figure 4. Reln ${ }^{-1-}$ embryos were included in this analysis as well, as useful paradigms.

In E19.0 normal embryos, E12.0 born neurons were clustered at two main radial levels. Approximately one-fourth of them, including presumptive Cajal-Retzius cells, lay underneath the pia mater; the rest was loosely clustered at the level of the SP. E13.5 and E15.0 born cells were located between the two main clustering levels of E12 born cells, and the E15 cohort lay prevalently superficial to the E13.5 one (Fig. 4a,c,e,i). In brief, as described previously, the neocortex is built-up biphasically and the $\mathrm{CP}$ is laid down according to the so-called "inside-out" rule (MarinPadilla, 1978, 1998, and references therein; Bayer and Altmann, 1991).

In E19.0 Emx $2^{-/-}$embryos, the majority of E12 born cells lay around the putative SP level (Fig. $4 b, j$ ), and their presumptive SP laminar identity was confirmed by colocalizing $\mathrm{CaR}$ with $\mathrm{BrdU}$ in a subset of them (data not shown); almost no E12 born cell were detectable at the marginal edge of the cortical wall (Fig. $4 b, h, j$ ). In the same embryos, both E13.5 and E15.0 born cells were scattered throughout the entire neocortical wall. A fraction of E13.5 and E15.0 cohorts lay marginally to the SP E12.0 cohort; however, the average distance between E13.5 and E15.0 born cells and the VZ was reduced, E13.5 and E15.0 populations were much more intermingled, and the inside-out rule was hardly followed (Fig. $4 d, f, j$ ).

This picture is somehow reminiscent of the reeler mutant cerebral cortex (Falconer, 1951; Caviness et al., 1988). However, a major difference takes place between Emx2 knock-out and reeler mice. In reeler mutants, CP neurons are not able to penetrate the preplate, which does not get split and gives rise to the so-called superplate (Fig. 4k). In Emx $2^{-/-}$embryos, CP neurons partially retain this ability so that a subplate can be distinguished from the subpial layer (Fig. $4 b, j$ ).

\section{Radial glia and migrating neurons in the mutant cortical plate}

In normal mouse embryos, regularly spaced radial glial bundles span from the ventricular to the marginal edge of the cortical wall since the very beginning of its development, and radially elongated neurons climb along the surface of these bundles during their translocation from the VZ up to the CP (Rakic et al., 1974; Caviness et al., 1988). At approximately E16.5, the average diameter of glial bundles varies dramatically around the SP (Fig. $5 a$ ) as a consequence of the defasciculation process that normally 

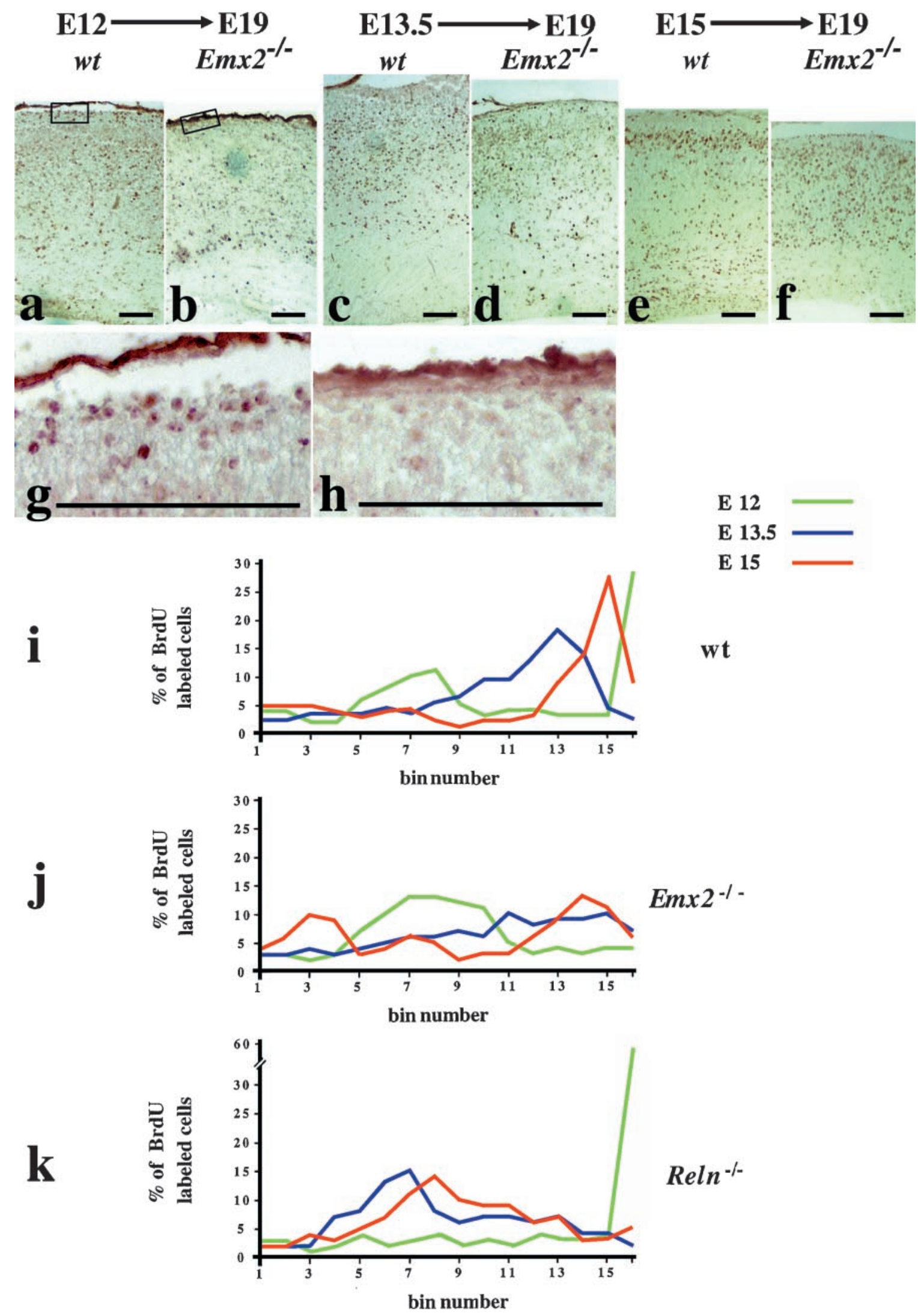

Figure 4. Radial distributions of E12.0, E13.5, and E15.0 BrdU pulse-labeled cells in the neocortex of E19 wild-type, Emx $2^{-/-}$, and Reln ${ }^{-/-}$mice. $a-h$, Photographic examples of radial distribution of BrdU on midfrontal neocortical sectors of E19 wild-type $(a, c, e)$ and $E m x 2^{-/-}(b, d, f)$ mouse embryos, pulse-labeled at E12.0 $(a, b), \mathrm{E} 13.5(c, d)$, and E15.0 $(e, f)$; in $g$ and $h$, there are magnifications of boxed areas in $a$ and $b$, respectively. $i-k$, Graphic synthesis of radial distributions of E12.0, E13.5, and E15.0 BrdU pulse-labeled cells in the neocortex of E19 wild-type $(i), E^{2} \times 2^{-1-}(j)$, and Reln ${ }^{-/-}(k)$ mice. Mice embryos were pulse-labeled at E12.0, E13.5, and E15.0 and harvested at E19.0. For each genotype and each labeling (Figure legend continues) 
Figure 5. Radial distribution of RC2 and MAP2 in the neocortex of E16E16.5 wild-type, $E m x 2^{-1-}$, and Reln $^{-\gamma}$ embryos. $a-f$, Radial glia in E16.5 wildtype (a), Emx2 $2^{-1-}(b)$, and $\operatorname{Reln}^{-1-}(c)$ embryos, stained by the monoclonal $\alpha$-RC2 antibody, rostral neocortex, frontal sections. In $c, d$, and $e$, there are magnifications of boxed areas in $a, b$, and $c$, respectively. In the normal cortex, the thick labeled glial bundles, which ascend from the ventricular toward the marginal zone, undergo a sudden reduction in their size at the level of the subplate $(a)$; in the cortical plate, they are regularly arranged and separated by relatively narrow interspaces (d, arrowheads). In Emx $2^{-1-}$ embryos, thick glial bundles ascend from the ventricular zone and enter the cortical plate; they are separated by wider interspaces (e, arrowheads) and do not undergo any appreciable reduction in width, while crossing the cortical plate $(b, e)$. Similar distribution of RC2 can be seen in $\operatorname{Reln}^{-1-}$ mutants $(c)$. In these animals, the glial bundles cross the entire cerebral wall and reach, still thick, the marginal layer commonly termed superplate $(c)$; relatively large interspaces are detectable among them, underneath the superplate ( $f$, arrowheads). $g-l$, Distribution of neuronspecific MAP2 immunoreactivity on frontal sections through rostral telencephalons of E16.0 wild-type $(g)$, $\operatorname{Em} x 2^{-1-}(h)$, and $\operatorname{Reln}^{-1-}(i)$ embryos; in $j, k$, and $l$, there are magnifications of the boxed areas of $g, h$, and $i$, respectively. In the case of wild-type animals, cortical plate neurons are prevalently fusiform and tightly clustered in a palisade-like structure; the marginal zone, less cellularized, displays intense $\alpha$-MAP2 immunoreactivity, possibly associated with terminal harborizations of cortical plate neurons apical dendrites $(j)$. In $E m x 2^{-1-}$ embryos, the cortical plate neurons appear more rounded and loosely distributed, and the marginal zone is more irregularly shaped $(k)$. All of that is somehow reminiscent of what can be seen in the Reln $^{-1-}$ neocortex at the level of the poorly laminated, broad layer replacing cortical plate and transitional field, as well as in the overlying superplate (l). $C P$, Cortical plate; $M Z$, marginal zone; $S b P$, subplate; $S p P$, superplate; $T F$, transitional field; $V Z$, ventricular zone. Scale bar, $100 \mu m$.
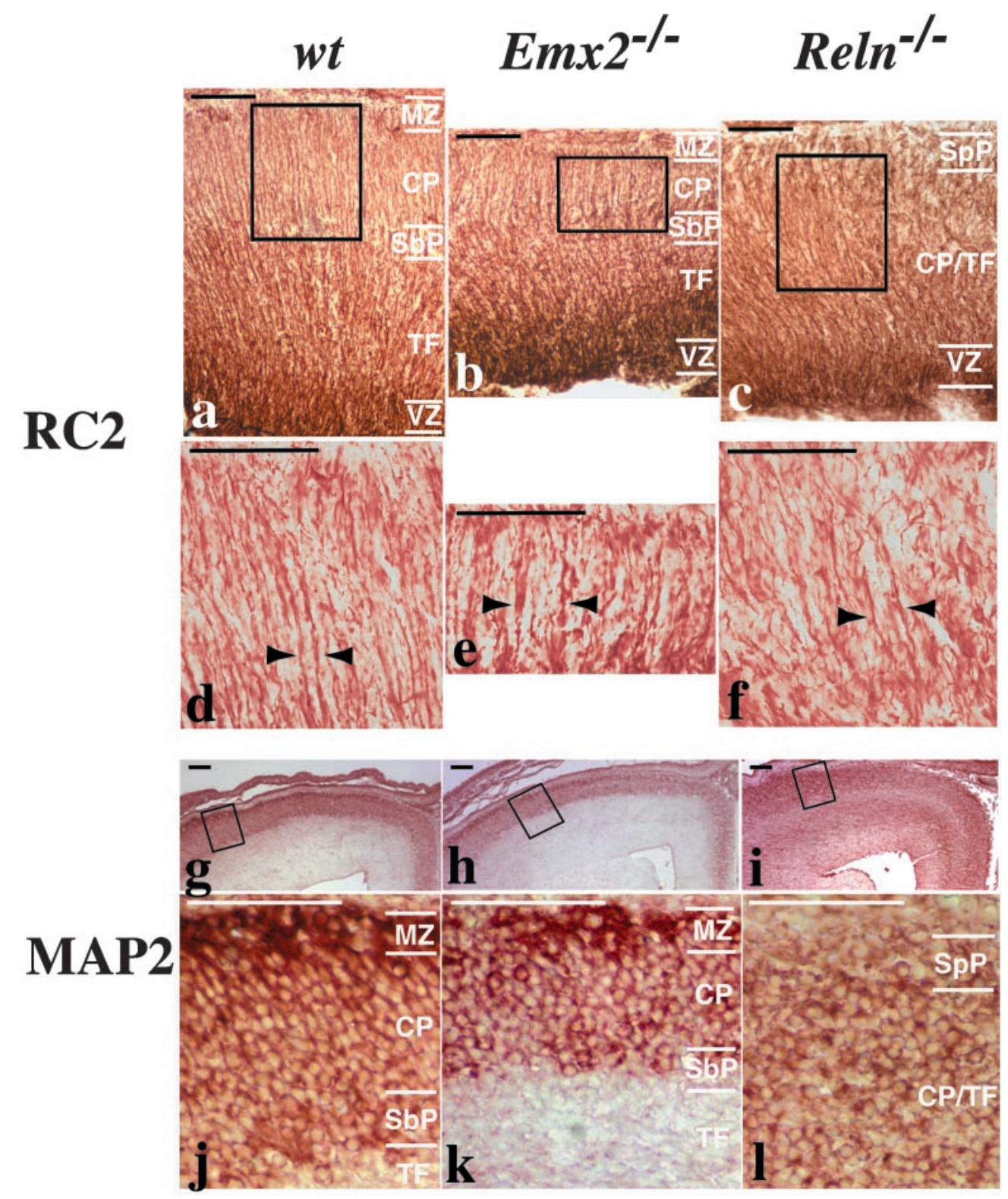

time, four animals were analyzed. Telencephalons were frontally sectioned, and the distribution of BrdU-labeled cells was scored in neocortical sectors at five standard rostrocaudal levels: anterior edge of the corpus callosum, rostral edge of the foramen of Monro, caudal edge of the foramen of Monro, anterior hippocampus, and posterior hippocampus. At each level, the neocortical sector was partitioned in 16 bins of equal radial width, which were numbered from ventricular to marginal, and the percentage of immunoreactive cells located in each bin was calculated. For all animals of a given genotype and BrdU-pulsed at a given time, we integrated data relative to these five rostrocaudal levels and represented the radial distribution of labeled cells by plotting the average percentage of labeled cells located in each bin against the bin number. Three triplets of colored graphs were obtained: green was used for representing E12.0 born cells, blue for E13.5 cells, and red for E15.0 cells. Finally, for each genotype, the three graphs were superimposed onto the same Cartesian plane, and the three pictures in the figure were obtained. In E19.0 normal embryos $(i)$, the graph referring to E12.0 born neurons gave rise to two peaks, a sharp marginal one corresponding to Cajal-Retzius cells, and a smooth intermediate one at the level of the SP. In the same embryos, both E13.5 and E15.0 graphs display one peak, falling between the two E12.0 peaks; the E15.0 peak is marginal to the E13.5 peak. In the case of Emx $2^{-1-}$ embryos $(j)$, the E12 graph gave rise only to a smooth peak, lying at the presumptive SP level; no trace of the normal marginal peak was detectable. In the same mutant embryos, considerable fractions of E13.5 and E15.0 born cells are located marginally to the smooth intermediate E12.0 peak. However, both E13.5 and E15.0 peaks are displaced toward the ventricular side of the $x$-axis, and the E13.5 and E15.0 populations are largely intermingled. In Reln ${ }^{-1-}$ mice $(k)$, all E12.0 born cells are clustered underneath the pia. All E13.5 and E15.0 born neurons lie deep to E12.0 born cells and are abundantly intermingled. Scale bar, $100 \mu \mathrm{m}$. 
occurs to radial glia at the level of the CP, between E15 and E17 in the mouse. This phenomenon consists in the separation between the 3-10 single cell fibers forming each primary glial fascicle and is associated with the penetration of each primary fascicle by radially migrating neurons (Gadisseaux and Evrard, 1985; Caviness et al., 1988). Subtle morphological abnormalities are displayed by radial glia of late gestation $E m \times 2^{-/-}$fetuses. In these animals, glial fascicles are, in general, less regularly organized (Fig. 5a,b), and it is possible to find thick bundles, separated by wider interspaces (Fig. 5, compare $e, d$ ), crossing the $\mathrm{CP}$ and reaching the MZ. These dysmorphologies are somehow reminiscent of the classical defasciculation defects displayed by radial glia in reeler embryos (Caviness et al., 1998) (Fig. 5c,f) and are suggested to underlie migration defects specific of these mutants (Caviness et al., 1988). It is conceivable that the absence of the REELIN protein is the common cause of late radial glia abnormalities in both reeler and Emx $2^{-1-}$ mice.

reeler-like abnormalities are also detectable in $\mathrm{CP}$ neurons of $E m \times 2^{-1-}$ embryos by $\alpha$-MAP2 immunostaining (Fig. $5 g-l$ ). At E16, the neocortical plate of mutant mice contains prevalently rounded neurons (Fig. $5 k$ ) instead of fusiform cells populating the wild-type plate (Fig. 5j). In addition, these neurons are loosely clustered so that $E m \times 2^{-1-} \mathrm{CP}$ lacks the tight and palisade-like architecture characterizing the normal plate (Fig. $5 j, k$ ).

\section{DISCUSSION}

\section{Impairment of Reelin expression in the neocortical marginal zone}

We have shown that $\mathrm{CaR}$ and Reln mRNA, normally coexpressed at high levels by neocortical Cajal-Retzius neurons of late gestation mouse embryos (Alcantara et al., 1998), are not detectable in the neocortical MZ of Emx2 knock outs. It is conceivable that Reln- and CaR-expressing neurons affected in mutant embryos correspond to the intensely $\alpha$-EMX2- $\alpha$-CaR-immunoreactive cells we described previously in the same area in wild-type embryos (Mallamaci et al., 1998). At the moment, however, it is hard to say why these two markers disappeared. It has been found that, in the rat, a large number of late CR cells are born at around a stage approximately corresponding to mouse E12 (Meyer and Fairèn, 1996). Given that and given the almost complete absence of E12 born cells in the MZ of late gestation mutant embryos (Fig. 4h), one could conclude that our failure to detect $\mathrm{CaR}$ and Reln mRNA in mutant mice could reflect the proper absence of the neurons normally expressing these markers. However, alternative explanations can be raised. For example, it is possible that neurons normally fated to express Reln, not properly differentiated and still surviving, were ectopically placed and/or heterochronically born. The ectopic hypothesis would be in keeping with the wider radial distribution displayed by E12 BrdU pulselabeled cells in E19 knock-out embryos compared with wild-type ones (Fig. 4i,j). About heterochronic birth, it has to be mentioned that numerous subpial neurons can be actually found by hematoxylin and cresyl violet staining (data not shown) in the neocortex of E19 mutant embryos and that, in the same animals, a small but substantive number of E13 (data not shown) and E13.5 (Fig. $4 d$ ) born cells settle just beneath the pia mater.

It is noteworthy that the impairment of Reln and CaR expression is restricted to mid-late phases of corticogenesis. No apparent differences in neocortical expressions of either Reln mRNA (Fig. $2 a, b)$ and CaR (data not shown), in fact, could be detected at E11.5 between wild-type and knock-out mice. What is the meaning of that? One could hypothesize that the same CR neurons do not require the products of Emx2 at the very beginning of their life and only subsequently become dependent on them for surviving and/or retaining their proper differentiation state. However, the overt increase of the absolute total number of Reln-expressing cells taking place in wild-type animals between E11.5 and E15 (data not shown; Alcantara et al., 1998), as well as E10.5-E19 (data not shown) and E12-E19 (Fig. 4g,h) birthdatingsurvival data, suggest that at least two different populations of Reln-expressing cells do exist, which can be operationally distinguished on the basis of their dependence on Emx2 function. We have an early transient population, prevalently generated before E11.0 and not dependent on the Emx2 function, and a late, still detectable at approximately birth, population, prevalently generated after E11.5 and dependent on the Emx2 function for crucial and still unknown steps of its development. Actually, two main neuronal populations were also described in the neocortical MZ of the rat. The first, early and transient, is generated in the neocortical VZ; the second, later born and longer surviving, has been proposed to arise in the basal retrobulbar region and to reach the neocortical MZ by subpial tangential migration. These two rat populations nicely correspond, for birthdating and survival profiles, to our MZ mouse populations (Meyer and Fairèn, 1996; Meyer et al., 1998); however, we think that it is premature to claim that a true homology takes place. Further experimental work, including DiI tracing tests, will hopefully make this point clear and will provide us with valuable suggestions about the key role(s) played by Emx2 in the development of the mouse secondary population.

\section{Axially restricted defects in the subplate}

We have shown that, in Emx2 mutant mice, the development of specific SP neuronal populations expressing CaR and EMX1 is impaired. The fact that these populations are affected, despite the absence of any expression of Emx2 in normal SP cells and the main restriction of EMX2 to the VZ (Gulisano et al., 1996; Mallamaci et al., 1998), suggests that this phenotype is attributable to the lack of critical functions played by Emx2 in SP neurons precursors, when they still lie in the VZ. Emx2 could normally either allow these progenitors to come out of the mitotic cycle at the proper time or play a crucial role in preparing the appropriate survival-differentiation programs of their postmitotic descendants.

These defects are not ubiquitous but are restricted to caudal and medial SP. Interestingly, in the cortical VZ, Emx2 displays a graded expression with caudomedial maximum and rostrolateral minimum (Mallamaci et al., 1998). Is there a link between axial restrictions in SP phenotypes and this expression gradient? Two simple explanations can be conceived. First, it is possible that Emx2 cooperates in an additive way with other genes, characterized by complementary expression patterns (e.g., Pax 6) (Walther and Gruss, 1991), in modulating the expression of a downstream effector necessary to prime the development of the affected SP neuronal population. In mutant embryos, the sum of Emx2 and, for example, Pax6 activities on this target should fall under the critical threshold near the posterior and medial edges of the cortical VZ in which normally Emx2 is more intensely expressed. Alternatively, it is possible that neurons belonging to an affected SP population and displaying different axial locations, even if sharing a given marker, are basically not homogeneous. At different locations along both main tangential axes, different doses of EMX2 might be necessary to their VZ forerunners for initiating their specific and different morphogenetic programs. If some functional interchangeability takes place between EMX2 and 
EMX1, it is conceivable that, in more rostral or lateral neuroblasts, the absence of EMX2 can be rescued by EMX1 protein, whereas this would not be possible in more caudal or medial neuroblasts because of the very high, unrescuable levels of EMX2 activity these cells require.

\section{Lack of Reln signaling and migratory abnormalities}

We found that radial migration of $\mathrm{CP}$ neurons is specifically impaired in Emx2 mutant mice. It is conceivable that intrinsic, cell-autonomous anomalies occurring in $E m \times 2^{-1-}$ migrating neurons could take a part in causing that; testing this hypothesis will be the aim of further experimental work. At the moment, however, a precise causal relationship between time-restricted impairment of Reln signaling from neocortical MZ and migratory phenotype occurring to $E m \times 2^{-/-}$mice can be already hypothesized.

MZ cells normally are the only effectors of the Reln function in the developing cerebral cortex, from at least E11.5 up to perinatal stages (D'Arcangelo et al., 1995, 1997; Hirotsune et al., 1995; Ogawa et al., 1995; D'Arcangelo and Curran, 1998) (Fig. 2e-g,k). It has been shown that mice constitutively lacking the Reln function display a severe neocortical migratory phenotype, including two main features. First, CP neurons do not penetrate the preplate, which is not split into $\mathrm{MZ}$ and SP and gives rise to the so-called superplate; second, during their radial migration, late born CP neurons do not overcome early born CP neurons and remain largely intermingled with them so that the classical insideout rule is not followed (Caviness et al., 1988) (Fig. 4i).

As shown, Emx $2^{-1-}$ mutants display a specific time and spacerestricted Reln functional knock-out. In the neocortical MZ of $E m \times 2^{-1-}$ embryos, Reln mRNA expression, apparently normal at E11.5, is reduced at E13.5 and completely absent since E15.5. In the same mutants, early phases of radial migration of CP neurons seem to be poorly affected, and late phases are impaired in a reeler-like way. Like the wild-type preplate, the Emx $2^{-/-}$preplate is penetrated by $\mathrm{CP}$ neurons so that an SP and an MZ can be distinguished; however, in the same mutants, late born CP neurons largely fail to overcome early born CP neurons (Fig. 4j) so that the inside-out rule is, again, hardly followed. It is possible that transient exposure to Reln signaling is sufficient to stably confer neurons fated to give rise to the SP the property to be able to be subsequently "overcome" by CP neurons, even at stages at which no more expression of Reln will be detectable. On the contrary, the reduction-absence of Reln products in the E13.5E15.5 MZ would account for the inability of the majority of E13.5 born neurons to let E15 born ones to settle superficially to them. Late absence of Reln products in the MZ would also account for abnormal neuronal packaging profiles, as well as for late radial glia dysmorphologies, occurring in Emx $2^{-/-}$mutants in a reelerrelated way (Fig. 5).

Finally, the possible role of nonmarginal Reln-expressing cells in the aethiology of migratory anomalies described above has to be mentioned. Nonmarginal Reln-expressing neurons normally appear in the outer CP at approximately birth (Schiffmann et al., 1997; Alcantara et al., 1998; Rice et al., 1998) (Fig. 2k), and it is likely that they could sustain the radial migration of last born neocortical neurons. It is possible that, in mutant $E m \times 2^{-1-}$ embryos, earlier appearance of nonmarginal Reln-expressing neurons (Fig. $2 h-j$ ), as well as their radial misplacement (Fig. $2 l$ ), could take part in causing the migratory abnormalities outlined above. Selective in vivo ablation of CP Reln signaling, as well as appropriate tests on brain slice cultures, will hopefully allow us to make this point clear.

\section{REFERENCES}

Alcantara S, Ruiz M, D'Arcangelo G, Ezan F, De Lecea L, Curran T, Sotelo C, Soriano E (1998) Regional and cellular patterns of reelin mRNA expression in the forebrain of the developing and adult mouse. J Neurosci 18: 7779-7799.

Anderson SA, Eisenstat DD, Shi L, Rubenstein JL (1997) Interneuron migration from basal forebrain to neocortex: dependence on $D l x$ genes. Science 278:474-476.

Antonini A, Shatz CJ (1990) Relation between putative transmitter phenotype and connectivity of subplate neurons during cerebral cortical development. Eur J Neurosci 2:744-761.

Bayer SA, Altmann J (1991) Neocortical development. New York: Raven.

Bovolenta P, Mallamaci A, Briata P, Corte G, Boncinelli E (1997) Implication of $O t x 2$ in pigmented epithelium determination and neural retina differentiation. J Neurosci 17:4243-4252.

Briata P, DiBlas E, Gulisano M, Mallamaci A, Iannone R, Boncinelli E, Corte G (1996) EMX1 homeoprotein is expressed in cell nuclei of the developing cerebral cortex and in the axons of the olfactory sensory neurons. Mech Dev 57:169-180.

Caviness VS, Crandall JE, Edwards MA (1988) The Reeler malformation. In: Cerebral cortex, Vol VII, Development and maturation of the cerebral cortex (Peters A, Jones EG, eds), pp 59-89. New York: Plenum.

D'Arcangelo G, Curran T (1998) Reeler: new tales on an old mutant mouse. Bioassays 20:1-10.

D'Arcangelo G, Miao GG, Chen SC, Soares HD, Morgan JI, Curran T (1995) A protein related to extracellular matrix proteins deleted in the mouse mutant reeler. Nature 374:719-723.

D’Arcangelo G, Nakajima K, Miyata T, Ogawa M, Mikoshiba K, Curran $\mathrm{T}$ (1997) Reelin is a secreted glycoprotein recognized by the CR-50 monoclonal antibody. J Neurosci 17:23-31.

Dalton D, Chadwick R, McGinnis W (1989) Espression and embryonic function of empty spiracles, a Drosophila homeobox gene with two patterning functions in the anterior-posterior axis of the embryo. Genes Dev 3:1940-1956.

Del Rio J, Martinez A, Fonseca M, Auladell C, Soriano E (1995) Glutamate-like immunoreactivity and fate of Cajal-Retzius cells in the murine cortex as identified with calretinin antibody. Cereb Cortex 1:13-21.

Easter SS, Ross LS, Frankfurter A (1993) Initial tract formation in the mouse brain. J Neurosci 13:285-299.

Falconer DS (1951) Two new mutants, "trembler" and "reeler", with neurological actions in the mouse house. J Genet 50:192-201.

Frantz GD, Bohner AP, Akers RM, McConnell S (1994) Regulation of the POU domain gene SCIP during cerebral cortical development. J Neurosci 14:472-485.

Gadisseaux JF, Evrard P (1985) Glial-neuronal relationship in the developing central nervous system. A histochemical-electron microscopy study of radial glial cell particulate glicogen in normal and reeler mice and the human fetus. Dev Neurosci 7:12-32.

Ghosh A (1995) Subplate neurons and the patterning of thalamo-cortical connections. In: Development of cerebral cortex, Acta of Ciba Foundation Symposium 193, pp 150-165. London: Ciba Foundation.

Gulisano M, Broccoli V, Pardini C, Boncinelli E (1996) Emx1 and Emx2 show different patterns of expression during proliferation and differentiation of the developing cerebral cortex. Eur J Neurosci 8:1037-1050.

Hirotsune S, Takahara T, Sasaki N, Hirose K, Yoshiki A, Ohashi T, Kusakabe M, Murakami Y, Muramatsu M, Watanabe S, Nakao K, Katsuki M, Hayashizaki Y (1995) The reeler gene encodes a protein with an EGF-like motif expressed by pioneer neurons. Nat Genet 10:77-83.

Lee MK, Tuttle JB, Rebhun LI, Cleveland DW, Frankfurter A (1990) The expression and post-translational modification of a neuron-specific b-tubulin isotype during chick embryogenesis. Cell Motil Cytoskel 17:118-132.

Mallamaci A, Iannone R, Briata P, Pintonello ML, Mercurio S, Boncinelli E, Corte G (1998) EMX2 protein in the developing brain and olfactory area. Mech Dev 77:165-172.

Marin-Padilla M (1978) Dual origin of the mammalian neocortex and evolution of the cortical plate. Anat Embryol 152:109-126. 
Marin-Padilla M (1988) Early ontogenesis of the human cerebral cortex. In: Cerebral cortex, Vol VII, Development and maturation of the cerebral cortex (Peters A, Jones EG, eds), pp 1-30. New York: Plenum.

Marin-Padilla M (1998) Cajal-Retzius cells and the development of the neocortex. Trends Neurosci 21:64-71.

Meiyer D, Graus A, Kraay R, Langveld A, Mulder MP, Grosveld G (1990) The octamer-binding factor Oct6: cDNA cloning and expression in early embryonic cells. Nucleic Acids Res 18:7357-7365.

Meyer G, Fairèn A (1996) Different origins and developmental histories of transient neurons in the marginal zone of the fetal rat cortex. Soc Neurosci Abstr 22:1014.

Meyer G, Soria JM, Martinez-Golan JR, Martin-Clemente B, Fairèn A (1998) Different origins and developmental histories of transient neurons in the marginal zone of the fetal and neonatal rat cortex. J Comp Neurol 397:493-518.

Misson JP, Edwards MA, Yamamoto M, Caviness VS (1988) Identification of radial glial cells within the developing murine central nervous system: studies based upon a new histochemical marker. Dev Brain Res 44:95-108.

Morita T, Nitta H, Kiyama Y, Mori H, Mishina M (1995) Differential expression of two zebrafish emx homeoprotein mRNAs in the developing brain. Neurosci Lett 198:131-134.

Ogawa M, Miyata T, Nakajima K, Yagyu K, Seike M, Ikenaka K, Yamamoto H, Mikoshiba K (1995) The reeler gene-associated antigen on Cajal-Retzius neurons is a crucial molecule for laminar organization of cortical neurons. Neuron 14:899-912.

Pannese M, Lupo G, Kablar B, Boncinelli E, Barsacchi G, Vignali R (1998) The Xenopus Emx genes identify presumptive dorsal telencephalon and are induced by head organizer signals. Mech Dev 73:73-83.

Patarnello T, Bargelloni L, Boncinelli E, Spada F, Broccoli V (1997)
Evolution of Emx genes and brain development in vertebrates. Proc R Soc Lond B Biol Sci 264:1763-1766.

Pellegrini M, Mansouri A, Simeone A, Boncinelli E, Gruss P (1996) Dentate gyrus formation requires Emx2. Development 122:3893-3898.

Rakic P, Steensas LJ, Sayre EP, Sidman RL (1974) Computer-aided three-dimensional reconstruction and quantitative analysis of cells from serial electron microscopy montages of fetal monkey brain. Nature 250:31-34.

Rice DS, Sheldon M, D'Arcangelo G, Nakajima K, Goldwitz D, Curran T (1998) Disabled-1 acts downstream of Reelin in a signaling pathway that controls laminar organization of the mammalian brain. Development 125:3719-3729.

Schiffmann SN, Bernier B, Goffinet AM (1997) Reelin mRNA expression during mouse brain development. Eur J Neurosci 9:1055-1071.

Shimamura K, Hartigan DJ, Martinez S, Puelles L, Rubenstein JLR (1995) Longitudinal organization of the anterior neural plate and neural tube. Development 121:3923-3933.

Simeone A, Gulisano M, Acampora D, Stornaiuolo A, Rambaldi M, Boncinelli E (1992a) Two vertebrate genes related to Drosophila empty spiracles gene are expressed in embryonic cerebral cortex. EMBO J 11:2541-2550.

Simeone A, Acampora D, Gulisano M, Stornaiuolo A, Boncinelli E (1992b) Nested expression domains of four homeobox genes in the developing rostral brain. Nature 358:687-690.

Walther C, Gruss P (1991) Pax6, a murine paired box gene, is expressed in the developing CNS. Development 113:1435-1449.

Yoshida M, Suda Y, Matsuo I, Miyamoto N, Takeda N, Kuratani S, Aizawa S (1997) Emx1 and Emx2 functions in the development of dorsal telencephalon. Development 124:101-111. 